Revista Brasileira de Ensino de Fúsica, v. 28, n. 2, p. 131-132, (2006)

www.sbfisica.org.br

\title{
Editorial
}

\section{Santos Dumont e a Física do vôo}

Este ano comemora-se o centenário do vôo do 14 Bis. Santos Dumont tem sido alvo de inúmeras homenagens em simpósios, exposições e livros. Entre estes últimos destaca-se o "Santos Dumont e a Física do Cotidiano", de Alexandre Medeiros ser lançado pela Livraria da Física. Uma cartilha "Santos Dumont e a invenção do avião", do Henrique Lins de Barros, está sendo distribuída pelo Ministério da Ciência e Tecnologia e pelo Ministério da Educação em todas as escolas do país. A Física na Escola terá número especial dedicado a Santos Dumont e à física do vôo. Eduardo Valadares está organizando um livreto com experiências simples para atividades em escolas. Há diversos sítios interessantes, em particular, o da Nasa (http://www.grc.nasa.gov/www/K-12/airplane/bga.html), com excelente material para ilustrar aulas, simulações interativas sobre sustentação de asas e a discussão de explicações mais incorretas comuns. Projetos sobre a dinâmica de fluidos, a sustentação de asas, e temas correlatos podem trazer motivação e tornar as aulas de física menos áridas.

Já em 1916, Einstein se indagava sobre a causa da sustentação das asas de "nossas aves e máquinas voadoras" e apontava: "Há uma falta de clareza em geral sobre esta questão. Devo confessar que não encontrei em algum lugar da literatura especializada mesmo a mais simples resposta. Espero, portanto, satisfazer alguns leitores ao tentar remediar esta deficiência com esta simples consideração sobre a teoria do movimento de líquidos". Possivelmente o problema maior com que se defrontava Einstein seria uma "explicação simples" da física do vôo, uma vez que os trabalhos de W. Kutta (1867-1944), N. Zhukowski (1847-1921) e principalmente do genial L. Prandtl (1874-1953) nos anos de 1902-1906 haviam contribuído de forma significativa para uma abordagem aplicada das complexas equações de Navier-Stokes.

A mais convencional e popular explicação da sustentação dos aerofólios é baseada no conhecido princípio de Bernoulli, segundo o qual maior velocidade do fluxo na parte superior da asa provoca uma pressão menor. A diferença de pressões sobre o aerofólio em virtude das diferentes velocidades do fluxo de ar acima e abaixo causa a força de sustentação aerodinâmica. Esta explicação tem sido contestada, por vários autores, inclusive nesta revista (K. Weltner et al. RBEF 23, 429 (2001)), que argumentam que a causa da sustentação é a aceleração para baixo do ar pelo aerofólio e as leis de Newton respondem diretamente pelo fenômeno. Alguns autores invocam o efeito Coanda para explicar o fato de que as linhas de fluxo permanecem muito próximas ao aerofólio quando o ar passa através dele (J. Raskin, Quantum 5, 5, setp-oct., 1994 ou http://jef.raskincenter.org/published/coanda_effect.html). Outros, marcadamente J.S. Denker, consideram esta tese puro devaneio (http://www.av8n.com/how/htm/spins.html\#sec_coanda). Existe um consenso de que a concepção de "igual tempo de trânsito" para a corrente do ar por cima e por baixo - que implicaria que a velocidade do ar na parte superior de uma asa assimétrica é maior do que na parte inferior porque percorre "um caminho mais longo" - está errada (como demonstram experiências em túneis de vento e simulações computacionais). Tirante este fato, o resultado de Bernoulli, nada mais do que o princípio de conservação de energia, pode ser invocado para explicar a força de sustentação como defendido coerentemente por C. Eastlake (Phys. Teacher 40, 166 (2002)) desde que a conservação da massa seja incluída na argumentação. Em tempo: Einstein usou o princípio de Bernoulli no artigo mencionado acima, sem saber que em 1904 A. Zahn havia, pela primeira vez, usado a equação de Bernoulli na aerodinâmica.

O tema é fascinante e a celebração do centenário do 14 Bis pode propiciar um bom momento para que a dinâmica dos fluidos volte a ter destaque nas disciplinas básicas de Física para cursos de Ciências e Engenharia.

Em agosto do ano passado, a Sociedade Brasileira de Física, em conjunto com o Ministério da Educação, promoveu um encontro de físicos, educadores e representantes do governo para avaliar a situação

Copyright by the Sociedade Brasileira de Física. Printed in Brazil. 
do ensino de Física no país. Temas como a formação de professores, a divulgação científica, a reforma universitária, a interdisciplinaridade no ensino, o emprego de novas tecnologias da informação, e a educação a distância foram discutidos amplamente com a audiência que lotou o anfiteatro do Centro Internacional de Física da Matéria Condensada da Universidade de Brasília. As principais conclusões e sugestões colhidas durante o evento constaram de um documento-síntese cujos pontos principais foram apresentados em editorial (RBEF 27, 311 (2005)). Esta edição traz artigos que resultaram das apresentações dos autores no evento. Um deles trata da formação de professores, por Oto Borges. Uma lúcida exposição conclamando os físicos profissionais, professores universitários, a seguirem os passos de eminentes colegas na busca de um ensino melhor de Física em nossas instituições. Dois outros são sobre a educação a distância (EAD). André Angotti relata suas experiências nesta modalidade de ensino e faz previsões realistas sobre número de professores para atender a demanda em futuro próximo. Silvio Cunha aponta algumas dificuldades na implementação da EAD no Brasil.

Nelson Studart Departamento de Física Universidade Federal de São Carlos 